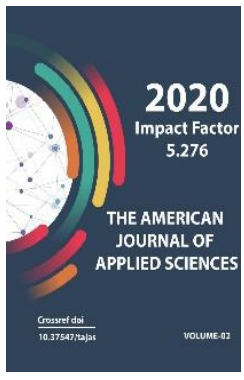

Journal Website: http://usajournalshub.c om/index,php/tajas

Copyright: Original content from this work may be used under the terms of the creative commons attributes 4.0 licence.

\section{Biological Efficiency Of New Insecticides Against Harmful Locusts In Uzbekistan}

\author{
Sanjar Usmanov \\ Andijan Branch Of Tashkent State Agrarian University, Andijan, Uzbekistan \\ Furkat Gapparov \\ Scientific-Research Institute For Plant Protection, Tashkent, Uzbekistan
}

\title{
ABSTRACT
}

More than 150 locust species are widespread in Uzbekistan, among them about 15 species can cause damage to agriculture every year, and they considered harmful. Among the harmful species of locusts, there are 3 species that can make a swarms. We have researched swarming locusts in the Andijan region of the Republic of Uzbekistan. Various types of chemical and microbiological insecticides are using to control of swarming locusts. In Uzbekistan, mainly used insecticides based on the Pyrethroid and Neonicotinoid groups. We have provide experiments to check the biological efficiency of insecticides "Aikido-Super" $10 \%$ e.c. and KARAT IKS $20 \%$ c.s. based on lambda-cygalothrin in various doses. According to the results of the experiment, insecticide Aikido-Super $10 \%$ e.c. and KARAT IKS $20 \%$ s.c. showed 97.6 and $96.3 \%$ biological efficiency at consumption rate of 0.065 and $0.0375 \mathrm{l} / \mathrm{ha}$.

\section{KEYWORDS}

Harmful locusts, swarming locusts, Moroccan locust, Italian locust, insecticides, locust control, insecticides, Piretroid, lambda-cygalothrin. 


\section{INTRODUCTION}

More than 150 locust species are widespread in Uzbekistan, among them about 15 species can cause widespread economic damage to the threshold every year (Tufliyev, 2019), but in Uzbekistan the most dangerous locust species are Asian locust (Locusta migratoria L. 1758)), Moroccan locust (Dociostaurus maroccanus (Thunberg, 1815)) and Italian locust (Calliptamus italicus (Linnaeus, 1758)). These species are gregarious. In CIS countries, the largest foci of the Moroccan locust are located in Uzbekistan (Gapparov, 2014).

In the eastern part of Uzbekistan, in the Andijan region, sometimes locust have outbreaks and damages to crops. Among these locust species, the most common gregarious species are the Moroccan locust and the Italian locust, and the solitary locust species. Along irrigation trenches and canals, fields in some years, solitary locust species, in particular, Caliptamus turanicus Serg. Tarb., Calliptamus barbarus cephalotes F.-W., Calliptamus italicus reductus Rme., also cause significant harm.

Historical foci of the Moroccan locust are located on the border of the Andijan region with Kyrgyzstan. Such places are mainly located in the Pakhtaabad, Khodjaabad, Izboskan and Khonabadt districts of the Andijan region. From 2018 to 2020, we were research distribution area and foci of locust in Ferghana valley. Non-gregarious locust species have been detected in all irrigated fields. In agricultural landscapes, the number of Italian and desert locust is $65.5 \%$ of the total number of non-gregarious locusts. At present, chemical insecticides based on pyrethroids and neonicatinoids are being treated against harmful locusts in Andijan region on 6000 hectares.
Synthetic pyrethroids are considered a promising pesticide with a pronounced insecticidal activity, low volatility, instability when exposed to light and low toxicity to mammals under normal conditions of use (WHO Report 1985). At that time, the drugs in the group of synthetic pyrethroids are degraded relatively quickly in water and soil. So, the complete destruction of permethrin in the soil occurs within 3 months. (Gordienko 1976).

In the mass breeding years of the Moroccan locust due to the flight from neighboring countries, the processing area will increase several times. According to the generally accepted method, chemical treatment is carried out in Uzbekistan, when the number of locust nymphs exceeds 10-15 units per $1 \mathrm{m2}$, depending on the state of vegetation and climatic conditions.

In the prohibition of the use of herbicides against weeds, the number of locust along the irrigation trenches the field and abandoned areas is increasing every year. Due to the lush development of weeds, the common areas of non-gregarious locusts are increasing every year.

\section{MATERIALS AND METHODS}

We carried out experiments to determine the biological efficiency of insecticides against harmful locusts (Fig. 1 and 2). Experiments were carried out according to the generally accepted method of conducting field experiments (Dospekhov 1985).

To determine the efficiency of the insecticide Karat iks 20\% s.c. (Good Job Industry LLC, Uzbekistan) with the active ingredient lambda-cygalothrin $200 \mathrm{~g} / \mathrm{I}$ and Aikido-Super 
$10 \%$ e.c. with the active substance lambdacygalothrin $100 \mathrm{~g} / \mathrm{I}$ (Samo Pharm Service LLC Uzbekistan) experiments carried out in the summer of 2019 In Andijan region, Republic of Uzbekistan. Researched consumption rate of the insecticide Kart iks is $20 \%$ s.c. is 0.0375 $0.0625 \mathrm{I} / \mathrm{ha}$, and for the insecticide AikidoSuper $10 \%$ e.c. is $0.065-0.125$ I / ha. In both experiments, the preparation Karache super $20 \%$ e.c. was used as a etalon at a consumption rate of $0.2 \mathrm{I} / \mathrm{ha}$.

Field experiments against 2-3 instar and 4-5 instar of gregarious locust pastures in foothill conditions. For spraying preparations, 200 liters / ha of working fluid are prepared. Spraying was carried out using an OVX-28 mounted sprayer attached to an MTZ 80 tractor. Counting in 3,12, 24, 48 and 72 hours after treatment.

Determination of biological efficiency according to the method developed by Kurdyukov (1986). For this, wire square frames with a side size of $50 \times 50 \mathrm{~cm}$ were used. The frames were thrown $2 \mathrm{~m}$ in front of the counting officer. At first, the number of individuals that jumped out of the frame was recorded. Then the number of dead individuals in the frame was counted. The sum of live (jumped out of the frame) and dead individuals was the initial number of locusts before processing.

On the treated area, 20 samples were taken diagonally, each evenly over the treated area. Biological effectiveness was determined by the formula below:

$$
\ni=\frac{B \times 100}{A+B}
$$
$\ni$ - biological efficiency,\%;
$B$ - the number of dead individuals in a square frame;
$A$ - the number of live individuals in a square frame.

\section{RESULTS AND DISCUSSION}

According to the data obtained from the experiments of the preparations, it was found that the insecticide Kart iks 20\% c.s. and Aikido-Super $10 \%$ e.c. is highly effective against younger (2-3) instars of gregarious locusts. At the same time, the biological effectiveness of the insecticide Kart iks is $20 \%$ c.s. at consumption rates of $0.0375-0.0625 \mathrm{l} / \mathrm{ha}$, it was $96.3 \%$ and $97.8 \%$, respectively, 24 hours after treatment. Also, a high biological efficiency (97.5\%) of nymphs and older (4-5) instars was recorded, where the insecticide Karat iks was applied at a rate of $0.0625 \mathrm{l} / \mathrm{ha}$. In the variant where Atilla super was used as a etalon, $10 \%$ e.c. the death of locust nymphs was observed up to $96.6 \%$.

Insecticide Aikido-Super 10\% c.e. also showed a high biological effect against 2-3 instars of gregarious locusts. At a consumption rate of $0.065 \mathrm{l} / \mathrm{ha}, 93.6 \%$ biological efficiency was obtained 3 hours after treatment. 24 hours after treatment received $97.6 \%$, and 72 hours after treatment received $90.6 \%$ biological effectiveness. Against the nymphs of 4-5 instars, the consumption rate was $0.125 \mathrm{l} /$ ha 3 hours after treatment, $91.4 \%$ of the biological effectiveness was obtained. 24 hours after 
The American Journal of Applied Sciences (ISSN - 2689-0992)

Published: September 30, 2020 | Pages: 299-303

Doi: https://doi.org/10.37547/tajas/Volume02Issue09-41

treatment received $97.1 \%$, and 72 hours after

effectiveness.

treatment received $89.4 \%$ biological

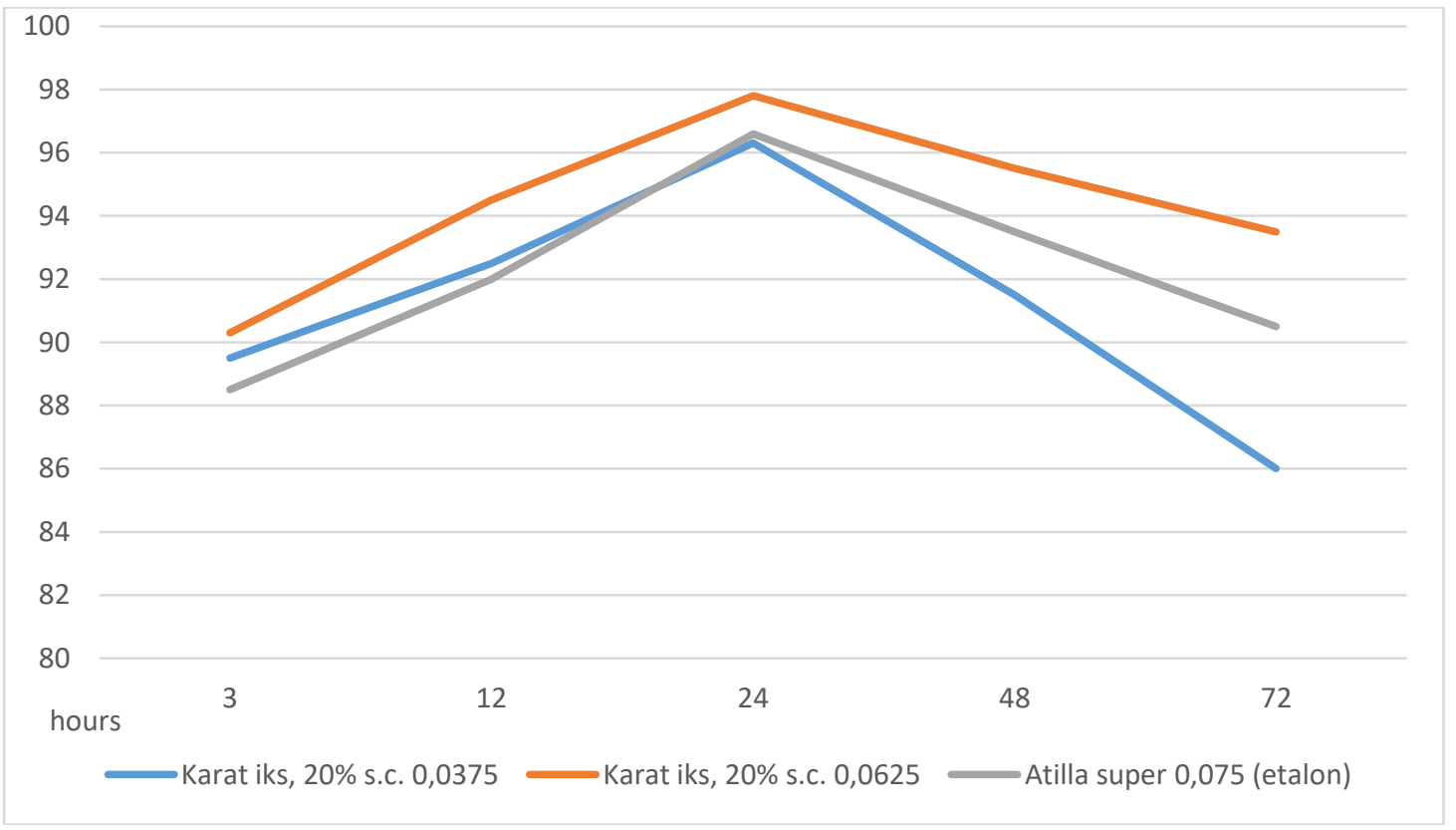

Fig. 1. Biological efficacy of the insecticide Karat iks, $20 \%$ s.c. against nymphs of swarming locusts.

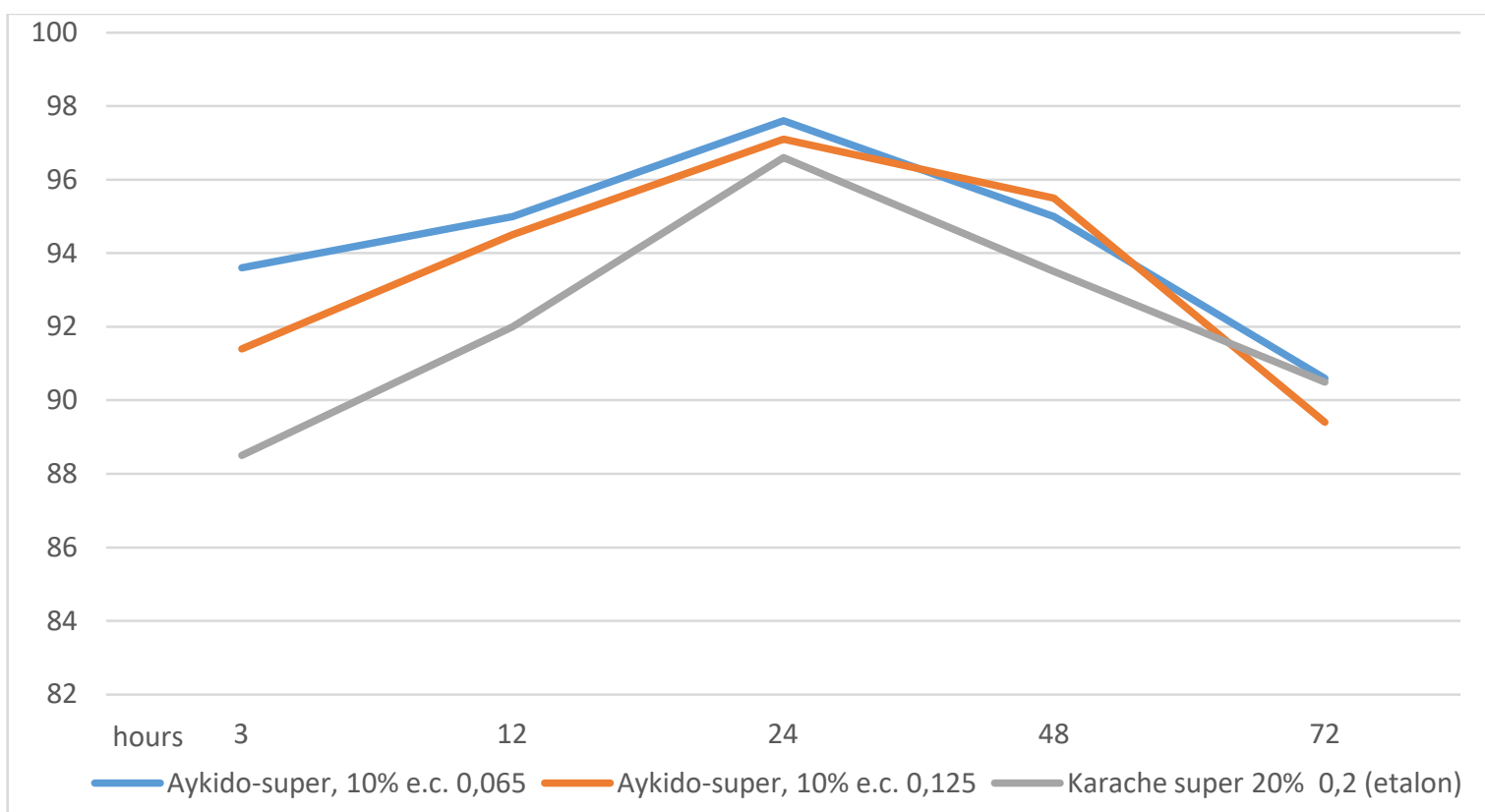

Fig. 2 Biological efficacy of the insecticide Aykido-Super, 10\% e.c. against nymphs of swarming locust 


\section{CONCLUSION}

Obtaining such a result allows us to consider that the use of the drug Karat iks, $20 \%$ s.c. at consumption rates of 0.0375-0.0625 and Aykido-Super $10 \%$ e.c. at rates of consumption of $0.065-0.125$ I / ha by the method of continuous processing of $1 /$ ha, provides a protective effect against younger and older instars of nymphs of gregarious locusts in Uzbekistan.

Based on the results of the experiments, it can be concluded that Karat iks, $20 \%$ s.c. at consumption rates of $0.0375-0.0625 \mathrm{I} / \mathrm{ha}$ and Aikido-Super $10 \%$ e.c. at rates of $0.065-0.125$ I/ ha can be recommended for use against nymphs of gregarious locusts in Uzbekistan.

\section{REFERENCES}

1. Kurdyukov V.V., Vasiliev S.V., Bunin L.D. Methodical recommendations for accounting for the number and assessment of the biological effectiveness of insecticides used in locust control. - L., 1986 .-- 22 p.
2. Gapparov F.A. Bioecological features of the development of harmful locusts in Uzbekistan and measures to combat them. - Tashkent: "Navruz", 2014. - 336 b.

3. Safe use of pesticides. Those. Report No. 720. Pyrstroids. - Geneva: WHO, $1985 \mathrm{~S}$.

4. Gordienko N.I. Migration of the herbicide prometrine in the external environment: Sat. works of scientific and practical. Conferences "Hygiene of human settlements" - M, 1976, pp.16-18.

5. Tufliev N.Kh. Creation of a complex for the fight against harmful locusts in the foothill, pasture and steppe zones of Uzbekistan, author's abstract of the dissertation of a doctor (dsc) of agricultural sciences. 06.01.09. Tashkent, 2019.- 69 p. (Uzbek, Russian language).

6. Dospekhov B.A. Field experiment technique. - M.: Agropromizdat, 1985.$432 \mathrm{p}$. 